\title{
The Effect of Suffusion Phenomenon in the Increasing of Land Subsidence Rate
}

\author{
Elmira Khaksar Najafi ${ }^{a^{*}}$, Hadi Faghihmaleki ${ }^{\text {a }}$ \\ ${ }^{a}$ Department of Civil Engineering, Ayandegan Institute of Higher Education, Tonekabon, Mazandaran, Iran
}

Received 20 April 2016; Accepted 15 June 2016

\begin{abstract}
Land subsidence is defined as gradually ground surface settlement in an aquifer due to the compaction of unconsolidated sedimentary deposits. Since in an aquifer, deposits consist of cohesive or non-cohesive alluvial soil layers. The consolidation theory cannot be explained as the only reason for land subsidence. According to the susceptibility of alluvial soils to suffusion, internal erosion is also considerable to enhance the rate of the local settlement. Suffusion is explained as a process of soil particle movement in the soil body due to the effect of seepage flow on it. The subsidence rate in southwest and south of Tehran in Iran is very considerable whereby some structures have suffered significant damages due to this phenomenon. In this research, the contribution of suffusion and land subsidence was investigated in damaged building located at Ghale Morghi Street in southwest of Tehran, as a case history. Because of the incapability of available methods, in this article, a probability pattern is also proposed using statistical analysis for determination the likelihood of internal instability in alluvial soils in regard to soil cohesiveness.
\end{abstract}

Keywords: Suffusion; Alluvial Soil; Land Subsidence; Statistical Analysis; Logistic Regression; Cohesiveness.

\section{Introduction}

In the recent decades, the excessive withdrawal of ground water resources owing to the population increment has wound up a challenging problem in the geotechnical engineering because of land subsidence, causing fundamental damages in arid and semi-arid regions. Land subsidence is defined as an environmental phenomenon, which causes ground surface to settle because of the compression of underground substances. Since unconsolidated sedimentary deposits constitute underground material in most aquifer, this phenomenon can be described in terms of the consolidation theory developed to illustrate the ejection of water from soils subjected to loading [1]. Even though a great deal of land subsidence can be explained by the consolidation theory, in special circumstances, other phenomena also contribute to the increment of land subsidence rate. Mexico City with maximum subsidence rate of $300 \mathrm{~mm} / \mathrm{yr}$ [2, 3], China with subsidence rate from less than 1 to more than $10 \mathrm{~mm} / \mathrm{yr}$ in 70000 square kilometers [4], Venice and Wairakei are famous examples for land subsidence [5]. Moreover, in Iran, this phenomenon has also occurred in Meshhed, Rafsinjan, Kerman, Hamadan (Kabodder Ahan Valley), Faminin and Tehran (Maain Abad and Varamin valleys), Arak, Nahawand, Khumain, Natanz, Yazd and Aber Kuh [6].The excessive pumping of groundwater will worsen if aqueducts exist in one aquifer. The lowering of groundwater surface brings about the space of the aqueducts formerly filled by water to be empty and leaves spacious canals through soil mass. These canals play an important role in the producing and increasing hydraulic gradient, leading to erosion. Unconsolidated sedimentary deposits in aquifers consist of cohesive and non-cohesive soils. For this reason, the consolidation theory is not the only reason for land subsidence. In regard to the existence of alluvial deposits in aquifers, the probability of internal erosion will be also considerable in such districts so that alluvial soils are intrinsically prone to occur suffusion because of being widegraded and low-compacted. In suffusion phenomenon, finer particle are removed through the voids of larger particle by seepage flow, and an intact soil skeleton formed by the coarser particle leaves behind, which is susceptible to settlement. Hence, both hydraulically and geometrically conditions are simultaneously requisite factors to transfer soil

\footnotetext{
${ }^{*}$ Corresponding author: khaksar@aihe.ac.ir
} 
particle through the soil structure. This shows, suffusion is an intricate phenomenon influenced by many elements such aggregation, porosity, compaction and cohesiveness of soil particle and seepage force within a soil mass. Various approaches presented were divided into geometric and hydraulic criteria in identifying suffusion occurring. USACE (1953), Isotomina (1957), Patrasev (1957), Ziems (1969), Kenny and Lau (1985) and (1986), Burekova (1993), Wan and Fell (2004a) and (2004b), Li and Fannin (2008) developed various geometric methods in the assessment of suffusion occurring [7-16]. The properties of soil aggregation, coefficient of uniformity $(\mathrm{Cu})$ and soil porosity (e) are the basic inputs used in the geometric available criteria and soil cohesiveness's effect has been ignored, although it is very effective in the occurrence of suffusion. In this research, firstly, both suffusion and land subsidence's effects were investigated in the one damaged building located at Ghale Morghi Street in the southwest of Tehran, and finally, a predicting pattern was suggested, which can determine the probability of internal stability using a statistical approach with regard to the effect of soil cohesiveness. And for any other project, this trend can be used to present a pattern in accordance with special situations of that project.

\section{Case History}

Tehran and suburbs are limited between south hillside of the Elburz Mountain range in the north of Iran, which is composed by unconsolidated alluvial deposits and north depression in Central Iran .Investigations show that there is a land subsidence in southwest and south of Tehran, located on Varamin valleys. The Extensive withdrawal of groundwater was proved by a fall of $13 \mathrm{~m}$ in Varamin valleys and the rate of subsidence in this district was reported nearly $23 \mathrm{~cm} / \mathrm{y}$ [17]. Buildings located on Ghale Morghi Street at district17 in the southwest of Tehran provinces were subjected to some damages. As was mentioned, this region is commonly a vulnerable area to subside in Tehran. Seemingly, reduction of groundwater level associated with collapse of aqueducts and subsurface erosion are the fundamental origins to subside land in most regions in the southwest and south of Tehran. The presence of aqueducts in this region has intensified the subsidence rate. Figure 1 shows the location of district 17 in Tehran provinces.

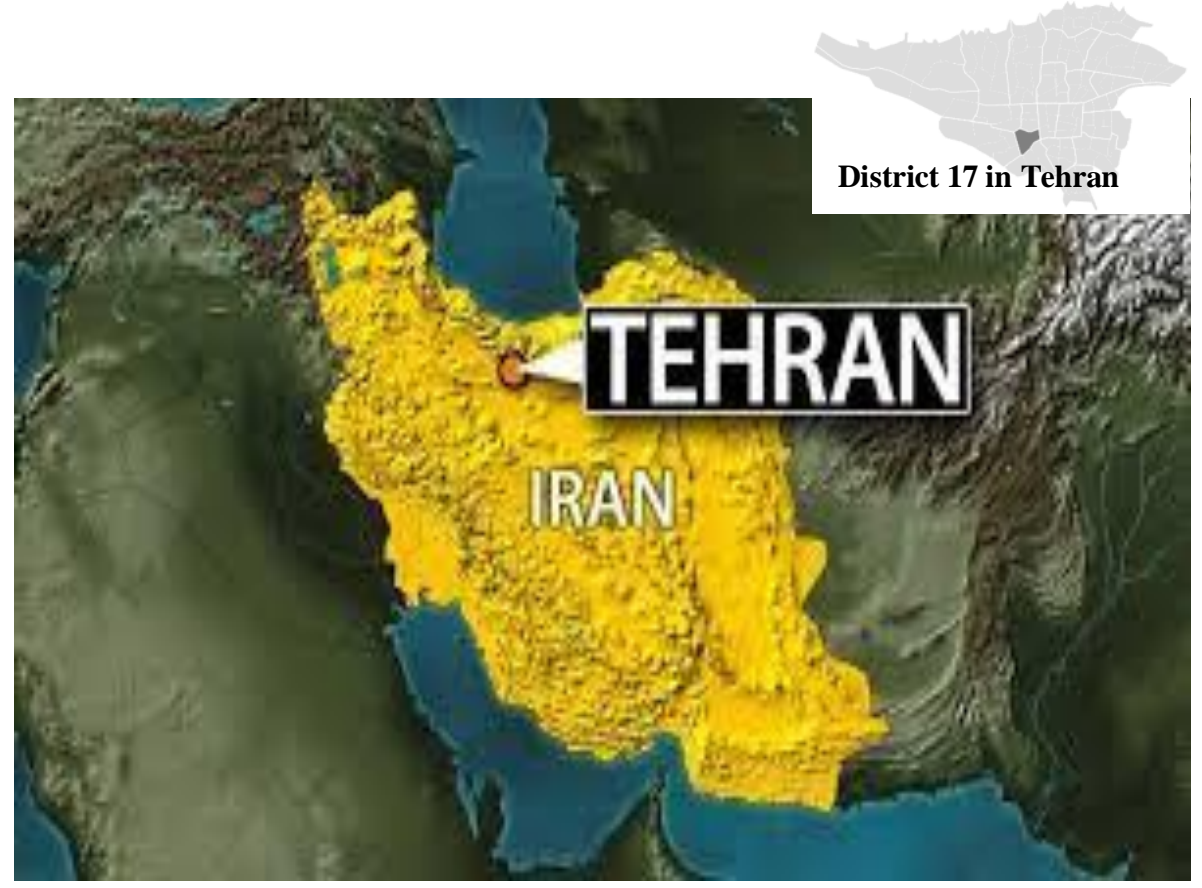

Figure 1. Location of district 17in Tehran, Iran

This area is considered as a main aquifer in the central of Iran. In this domain, aqueducts constituted $40 \%$ of groundwater sources. The exploitative pumping of deep and semi-deep wells has caused ground water surface to decline and aqueducts have been become empty. Therefore, empty aqueducts and damages related them were taken into account as a common feature in this region so that considerable number of structures located on the surrounding of Ghale Morghi and Ghazvin and Abouzar Street have suffered considerable damages. Based on geotechnical investigations conducted, soil profile of this area consists of construction waste at superficial depths and layers of silt associated with fine sand at deeper depth. In some depths, low plasticity clay with some fine sand and fine sand with low plasticity clay was also observed in different thickness. One typical soil profile of this district is presented in Table1. Generally, investigations done by others show soil deposits in south and southwest of Tehran are constituted of the unconsolidated alluvial soils assorted as fine graded silt and clay category similarly to river bed sedimentary. In this region of Tehran, the ranges of plasticity index (PI) and percent of finer particle passing of sieve No. 200 are from 12 to 25 and from 50 to 80, respectively [18]. Based on the range of PI in this district of Tehran, the main type of clay 
minerals consists of kaolinite [19]. Regarding the soil type-alluvial soils with low plasticity and compaction- the probability of soil instability would be considerable.

Table 1. Gale Morghi Street soil profile

\begin{tabular}{cccc}
\hline Depth & Soil & LL & SPT \\
\hline $0-8$ & construction waste & - & - \\
$8-10$ & Silt associated dark sand- ML & 38 & 14 \\
$10-14$ & Clay associated fine sand- CL & - & - \\
$14-15$ & Silt associated brown clay and fine sand- ML & 31 & - \\
$15-30$ & Brown clay associated a little fine sand-CL & - & $10-35$ \\
\hline
\end{tabular}

One building that an aqueduct discovered at its site was investigated to distinguish the contribution of suffusion and land subsidence in observed damages. First evidence on the presence of aqueduct related to the drilling a well at the site of these buildings in 2005. Suddenly, a huge hole was observed at depth of $-80.50 \mathrm{~m}$ in the northeast corner of the structure. This hole was similar to a continuous canal from earth surface to deeper level, which had been partly filled by soil particle. This was a strong evidence to erode soil particle. The partial section of the hole has passed from the beneath of the structure's foundation so that some part of foundation had established on the void space without any appropriate support. Figure 2. shows the observed hole at the building site. Based on the conducted surveys, sever cracks were observed at walls of a garage located near the building. Figure 3 shows the cracks on the garage wall. Sidewalk in the front of this building and some trees located on the southwest corner of that also settled. In addition to this building, some residential building located on Ghale Morghi Street has suffered severe damages such as settlement and cracks on peripheral walls and foundation of structure.

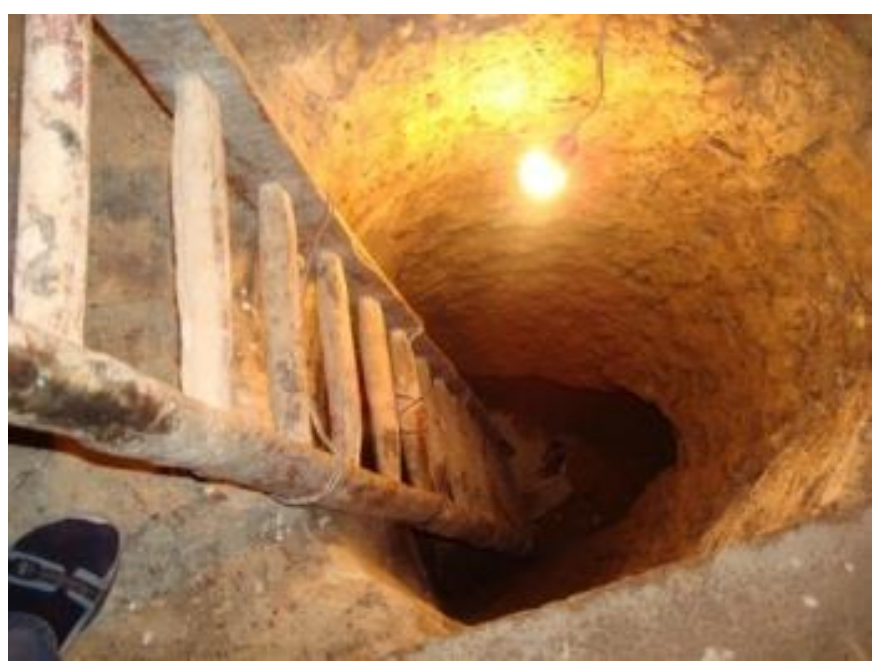

Figure 2. The hole at the mentioned site

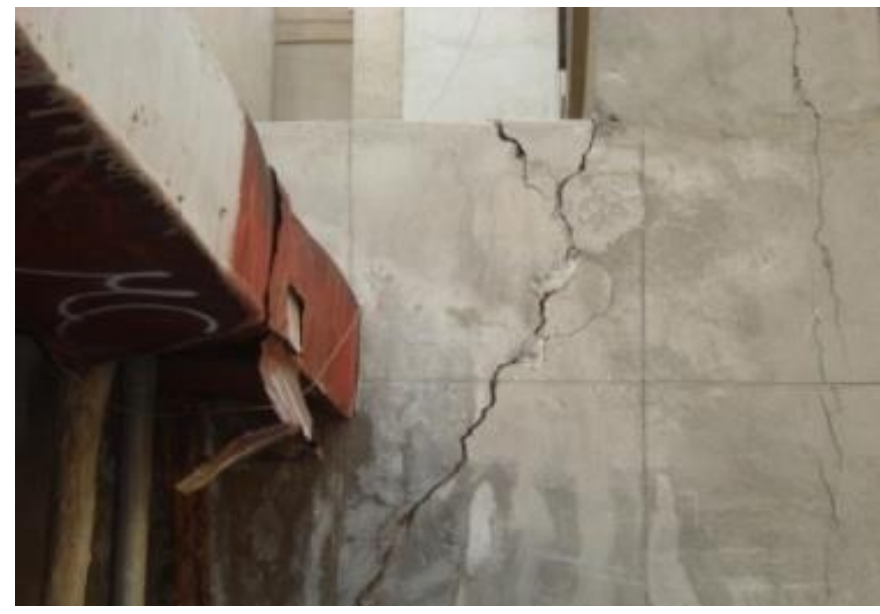

Figure 3. Cracks on wall of garage near the mentioned building 


\subsection{Assessment of Reasons for Soil Erosion at the Mentioned Site}

To assess subsidence reasons in this region, both geotechnical and hydraulic evaluations were conducted. Based on the soil profile, erosion could be concerned to collapsibility, leaching and suffusion phenomena. According to the classifying soil profile as the fine-graded alluvial soils, the occurrence of internal erosion due to suffusion would be possible. Regardless of experimental studies, the probability of collapsibility and leaching was cancelled because the aqueducts were full of water many years ago, so the occurrence situation for both phenomena was available. It has been accepted that collapsive and dissolvable soil would be stable after soil saturation and their occurrence. Furthermore, on condition that the reason for the damages was related to collapsibility and leaching, their effects would be also seen in unpopulated and surface areas, especially after seasonal rainfall due to soil drought. In regard to hydraulic evaluation, groundwater direction was compatible to the ground slope from the northwest to the southeast in the mentioned region. Investigation conducted showed aqueducts direction often was similar to the ground slope from the northwest to the southeast direction, which could provide hydraulic gradient and causes water penetration and groundwater to flow through these abandoned aqueducts. The water resources in this region are mainly formed by the surface water flow from the north and to a less extent from the seasonal rivers and surface seepage. Rivers provided through snow melting from north, northeast and northwest highlands of Tehran flow into the Varamin plain, which create underground water flow into these abandoned aqueducts [20]. Likewise, the presence of construction waste at superficial layers has resulted in the increasing of soil permeability leading to the penetration of surface water flow in to soil mass. Direction of the aqueducts in district 17 in Tehran is shown at the map presented by Tehran Disaster Mitigation and Management Organization in Figure 4 (TDMMO) [21].

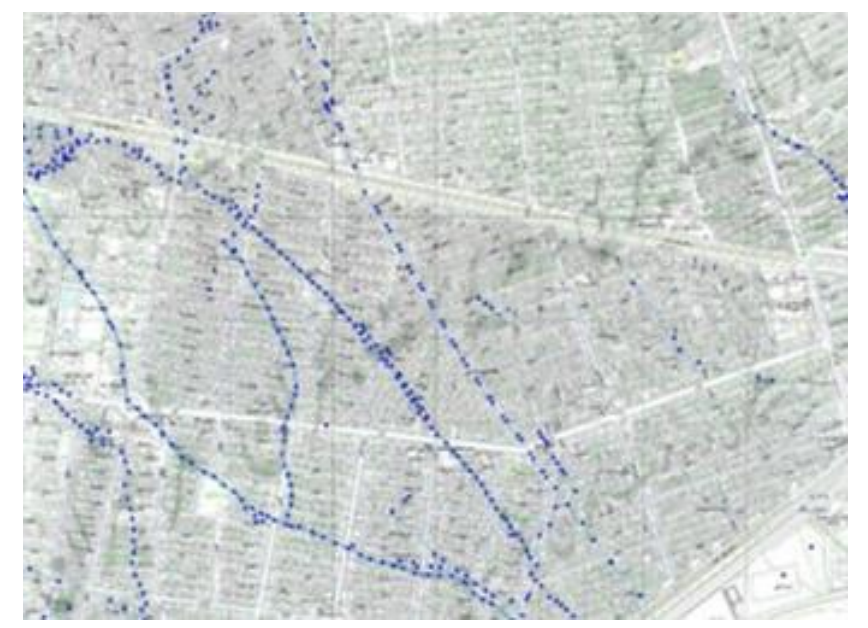

\section{Figure 4. Northwest to southeast direction of aqueducts in district 17 of Tehran}

Groundwater level was measured from 16 to $18 \mathrm{~m}$ in borehole drilled. According to the establishment depth of the aqueducts from 8 to $10 \mathrm{~m}$, the declining of the groundwater level has resulted in the abandoning of aqueducts through some years ago. Generally, investigation showed empty aqueducts and their similar direction to the ground slope have caused hydraulic gradient to transfer water flow through these aqueducts. Accompanied by water flow, erodible particle of sand and silt layers have been eroded into the aqueducts, filling part space of aqueducts. Gradually, the progressing of this trend leads to the enhancement of soil porosity and differential settlement. In fact, in this case, soil erosion because of the suffusion phenomenon, caused subsidence rate to enhance. According to this fact that establishment depth of aqueducts was parallel to silt layers, so abandoned aqueducts have generated more appropriate condition for soil erosion. Generally, aqueducts could cause subsidence in two ways. First, collapse in aqueducts can generate local subsidence especially in districts 17 . Second, underground aqueducts similarly to canals create suitable places for accumulation of erodible soil due to underground lateral flows and sewage. So subsurface erosion accelerates the subsidence rate [22]. For this reason, the soil's vulnerability to suffusion was investigated in this site.

\section{Databases}

In this research, 62 soil samples were collected from 12 references. Among them, 41 samples (66\%) experimentally subjected to suffusion by others and 21 remaining cases (34\%) have been considered as internally stable soils. Nearly, all of them have some percent of kaolinite clay to simulate clay mineral in this case study. A summary of database is shown in Table 2. These samples were collected from previous studies done by others. More details of samples are available in the related references. 
Table 2. References OF Database

\begin{tabular}{lc}
\hline \multicolumn{1}{c}{ Reference } & Sample Number \\
\hline Ke and Takahashi (2011) [23] & 8 \\
Richards and Reddy(2012) [24] & 4 \\
Nguyen (2012) [25] & 2 \\
Wan, and Fell.(2004) [14, 15] & 6 \\
Terzariol (2013) [26] & 2 \\
Wojtasik (2008) [27] & 3 \\
Chen. etc.(2008) [28] & 7 \\
Sun (1989) [29] & 16 \\
Hwiyhat [30] & 2 \\
Burekova (1993) [13] & 8 \\
Moffat and Fannin (2011) [31] & 4 \\
\hline \multicolumn{1}{c}{ Total } & $\mathbf{6 2}$ \\
\hline
\end{tabular}

\section{Statistical Analysis Results}

There is some truth in the fact that cohesiveness of soils is a momentous factor to soil instability so that its increment improves the stability condition of soils. The erosion rate of cohesive soils is attributed as a function of its clay content. Both type and amount of clay must be considered in the assessment of clay's effect in a soil. The Atterberg limit is very useful to reflect both of them. Generally, the erosion rate doubles when the clay content decreases from $20 \%$ to $10 \%$ [32], however Hassan Rahimi (2004) introduced the parameter of cohesive potential as $(\mathrm{LL} \times \mathrm{F})$ depending on $\mathrm{d} 50$ for evaluation suffusion occurrence [33]. Where LL, $\mathrm{F}$ and $\mathrm{d} 50$ are liquid limit, clay percent and particle sizes corresponding to $50 \%$ finer, respectively. Whereby, the decreasing of d50 accompanied by the increasing of cohesive potential enhanced the suffusion probability. This means, a cohesive soil would be also prone to suffusion if other required parameters such as soil aggregation were available. Regarding to the lack of the available geometric criteria in identifying internally unstable soils in regard to clay percent of a soil, in this research was tried to propose a predictive pattern in regard to the effect of soil cohesiveness. Wan and Fell (2004b) showed that among the various predictive criteria, Kenney and Lau (1986) and Burekova (1993) methods are comparatively more accurate [15]. The letter is less conservative and the former is more accurate to predict suffusion. In Kenney and Lau (1986), grading curve must be separated into two coarse and fine sections that are prone to error, and Burekova method sometime considers unstable soils as stable ones [12]. According to Burekova method (1993) a soil will be internally stable if it satisfies following inequality. Where $h^{\prime}=d 90 / d 60, h^{\prime \prime}=d 90 / d 15$ and d90, d60 and d15 are the particle sizes corresponding to 90,60 and $15 \%$ finer, respectively [13].

$0.76 \log \left(h^{\prime \prime}\right)+1<h^{\prime}<1.86 \log \left(h^{\prime \prime}\right)+1$

However, parameters used in Burekova (1993) method are the results of mechanical sieve analysis, which is more accessible and accurate than any parameters. Thus, it will be reasonable if the modified parameters used in Burekova criterion are functioned to present a new predictive pattern for evaluating the suffusion possibility. Accordingly, the accuracy of Burekova criterion was investigated for the presented samples in this research. Results showed that 14 unstable samples and 8 stable samples mistakenly were taken to account as stable and unstable ones, respectively. This indicates, this method has accurately predicted $64 \%$ of samples. Based on the insufficient accuracy of Burekova criterion, and due to the investigation of the suffusion's effect on the rate of subsidence phenomenon in alluvial soils consist of clay, in this article, we tried to propose a predictive pattern in regard to soil cohesiveness. Accordingly, clay percent, $h^{\prime}$ and $h^{\prime \prime}$ were considered as the influential factors for prediction of suffusion probability by logistic regression analysis. For a database, the binary logistic model is employed to evaluate the probability of a binary response according to one or more predictor and variables. It assesses the relationship between the definite dependent variable and one or more independent variables by estimating probabilities using a logistic function. [34]. in this research the mentioned analysis has be done using SPSS software. To find an appropriate equation, different relations among them were investigated by binary logistic regression and insignificant relations were ignored by the Wald statistic. Finally $\sqrt[6]{\left(h^{\prime \prime} / \exp (C)\right)}$ and $\exp (C)$ were introduced as productive variables due to significance values 0.003 , less than 0.05 . This means that, these parameters lead to acceptable prediction based on following equation. So, logistic regression equation 2 was presented to predict suffusion probability in regard to soil aggregation and cohesiveness.

$p_{f}=\frac{\exp (Z)}{1+\exp (Z)} \rightarrow Z=0.386\left(\sqrt[6]{\left(h^{\prime \prime} / \exp (C)\right)}-11.72(\exp (C))+11.42\right.$

Where, $\mathrm{Pf}$ is the predicted probability of internal stability, $\mathrm{Z}$ is the dependent variable of the logistic regression equation and $\mathrm{C}$ is clay percent in a soil. Overall prediction $76 \%$ was computed for this equation, which is more accurate than Burekova criterion. 


\section{Result and Discussion}

\subsection{Proposed Predictive Pattern}

Generally, in the evaluation of suffusion possibility, the presentation of a comprehensive creation which satisfies in all projects and situations is impossible. Because of this fact, the presentation of a new creation is not the goal of this paper. Instead, in this paper has been tried to introduce a predictive pattern using statistical analysis. These trend similarly others geometric criteria just uses data of sieve analysis to establish a pattern. In this way, sieve analysis data as a simplest test done in any project, associated by statistical analysis can be used to propose a pattern for any project, individually. This trend decreases the number of required testing and allows considering appropriate parameters in regard to soil type in predictive pattern to assess suffusion possibility. Meanwhile, logistic regression is more useful due to the ability of considering of both unstable and stable soils into calculation of suffusion probability. The more variety of soils, the more inefficiency of available criteria, which emphasizes to predict an overall pattern for evaluating the probability of suffusion occurring. In addition to predictive patterns, site investigations and observations including the water flow pattern, water seepage, soil type and surface and subsurface erosion pattern could be very useful in the assessment of suffusion occurring.

\subsection{Assessment of Suffusion at the Site of Ghale Morghi Street}

Similar to Shahriyar County [35], in this case study, suffusion has occurred in non-hydraulic structures in urban area such as residential buildings. So as to assess the possibility of suffusion in this site, some soil samples contenting lay were selected. The probability of suffusion occurrence for samples was investigated using the Burekova criterion (1993) and the proposed predictive pattern. Based on the results presented in Table 3, the likelihood of the suffusion occurring in the Ghale Morghi Street area is considerable. Where h'=d90/d60, h" $=\mathrm{d} 90 / \mathrm{d} 15$ and d90, d60 and d15 are the particle sizes corresponding to 90,60 and $15 \%$ finer, respectively, and Pf is the predicted probability of internal stability.

Table 3. Assessment of Suffusion occurring in the Site of Ghale Morghi Street

\begin{tabular}{ccccc}
\hline $\mathbf{h}^{\prime}$ & $\mathbf{h}^{\prime \prime}$ & Clay percent & $\mathbf{P}_{\mathbf{f}}$ & Burekova criterion \\
\hline 5.67 & 161.9 & 19 & 0.13 & Unstable \\
1.15 & 106 & 8 & 0.39 & Unstable \\
1.67 & 4 & 5 & 0.39 & stable \\
2.86 & 100 & 21 & 0.09 & Unstable \\
\hline
\end{tabular}

\subsection{The Contribution of Suffusion and Land Subsidence in the Observed Damages}

According to the previous section and available evidences, suffusion occurring is probable in the soil of Ghale Morghi Street.Generally, alluvial soils are inherently prone to suffusion, especially in dry and semi-dry regions even due to a slow seepage force. In fact, land subsidence has provided requisite factors to suffusion occurring by lowering water table surface and generating water flow. Dry alluvial soils could be eroding by suffusion even if slow hydraulic gradient produced through a soil mass. Hydraulic gradient also generated by surface water flow, sewage seepage and flowing seasonal rivers from north highlands into this abandoned aqueducts. Furthermore, the lowering of ground water level produced hydraulic gradient, which could erode vulnerable soil to suffusion. Situations in this case study are similar to Shahriyar County in Tehran province located on the southern slopes of the Alborz Mountain range in regard to soil type and groundwater level. In spite of soil drought, water leakage from underground was mentioned as important reason for the suffusion occurring [35]. Based on these two case studies, suffusion phenomenon would be a probable in the south of Tehran. As was mentioned in the "Case history" section, although the occurrence of subsidence in south and southwest of Tehran is strongly accepted, statistical analysis and forceful evidence prove suffusion occurring in the Ghale Morghi Street. Based on the available evidence, the majority of damages were seen at the surrounding of residential building, which the penetration of water seepage and sewage into the soil mass could be more than unpopulated regions. It can be another reason for the contribution of suffusion phenomenon in the observed damages.Generally, the producing of overall settlement is more critical and frequent in land subsidence phenomenon. In contrast, suffusion provides local settling caused by erosion. So, local cracks and settlement could be increased by suffusion erosion. Due to the extension of the damage by land subsidence, the effect of suffusion would be often ignored. More importantly, soil type in an aquifer's deposits, which land subsidence occurred, is another reason for negligence of the probability of suffusion occurring related to non-cohesive soils.

\section{Conclusion}

In southwest and south of Tehran, the exploitative pumping of ground water surface has caused aqueducts to be abandoned whereby serious damages have been taken into account as a common feature in structures located on Ghale Morghi, Ghazvin and Abozar Street, such as mentioned building. Evidently, land subsidence is a main reason to damage; however, there is some evidence to attribute the effect of soil erosion on observed damages. In regard to the 
existence of unconsolidated alluvial soils with low plasticity and compaction, the probability of soil instability is considerable. Owing to the presence of clay in the soil profile, in this paper has been tried to consider cohesiveness in the evaluation of suffusion probability. According to this fact that parameters used in Burekova method is more accurate rather than other geometrical criteria, h' and h" can be considered as influential factors to predict suffusion. Using binary logistic regression and were presented as productive factors due to significance values 0.003 . Burekova method and predictive pattern accurately predict $64 \%$ and $76 \%$ of samples, respectively. This is why predictive pattern can be utilized with more precise in evaluating the probability of suffusion occurrence in regard to soil cohesiveness. And for any other project, this trend can be used to present a pattern in accordance with special situations of that project. Finally, according to the Burekova method and proposed predicted pattern, the soil samples of Ghale Morghi Street area were considered as internally unstable. Thus, suffusion accompanied by land subsidence brings about damages such as crack and settlement. Abandoned aqueducts have two effects in this case. The first was related to the increment of local land subsidence rate because of the collapse of aqueducts. Furthermore, they can generate and increase hydraulic gradient and water flow into empty canals, which leads to soil erosion in a vulnerable deposit. Owing to the presence of alluvial soils in the aquifer and regarding this fact that groundwater pumping is more frequent in dry and semi-dry region, suffusion probability can be considerable as a destructive phenomenon, in such condition. Accordingly, based on introduced case study in this paper, suffusion occurring is very likely in a region subjected to land subsidence. Land subsidence can provide requisite parameters to occur soil erosion by suffusion. Similarly to Shahriyar County located on the south of Tehran province, in this case study, soil is also vulnerable to suffusion. Based on these two case study, suffusion phenomenon would be a probable in south of Tehran.

\section{References}

[1] Miyabe, Naomi. "Directions of research on land subsidence." Land subsidence/affaissement du sol 88 (1970): 89.

[2] Chaussard, Estelle, Shimon Wdowinski, Enrique Cabral-Cano, and Falk Amelung. "Land subsidence in central Mexico detected by ALOS InSAR time-series." Remote sensing of environment 140 (2014): 94-106.

[3] Osmanoğlu, Batuhan, Timothy H. Dixon, Shimon Wdowinski, Enrique Cabral-Cano, and Yan Jiang. "Mexico City subsidence observed with persistent scatterer InSAR." International Journal of Applied Earth Observation and Geoinformation 13, no. 1 (2011): 1-12.

[4] Xue, Yu-Qun, Yun Zhang, Shu-Jun Ye, Ji-Chun Wu, and Qin-Fen Li. "Land subsidence in China." Environmental geology 48, no. 6 (2005): 713-720.

[5] Teatini, P., L. Tosi, T. Strozzi, L. Carbognin, G. Cecconi, R. Rosselli, and S. Libardo. "Resolving land subsidence within the Venice Lagoon by persistent scatterer SAR interferometry." Physics and Chemistry of the Earth, Parts A/B/C 40 (2012): $72-79$.

[6] Ghorban beige, S., and Naji Hamodi, J. Land subsidence in Tehran district, Iran. In Proceeding of 6th International Conference on Case Histories in Geotechnical Engineering, (2008).

[7] Engineers, US Army. "Filter Experiments and Design Criteria." Waterways Experiment Station, Vickburg, Miss, Technical Memorandum 3-360 (1953): 52.

[8] Istomina, V. S. "Filtration stability of soils." Gostroizdat, Moscow, Leningrad 15 (1957).

[9] Patrašev, A. N. "Motedika podbora granulometričeskogo sostava obratnych fil'trov." Sbornik trudov Lengiprorečtransa (1957).

[10] Ziems, Jürgen. "Beitrag zur Kontakterosion nichtbindiger Erdstoffe." PhD diss., 1969.

[11] Kenney, T. C., and D. Lau. "Internal stability of granular filters." Canadian geotechnical journal 22, no. 2 (1985): $215-225$.

[12] Kenney, T. C., and D. Lau. "Internal stability of granular filters: Reply." Canadian Geotechnical Journal 23, no. 3 (1986): 420423.

[13] Burenkova, V. V. "Assessment of suffusion in non-cohesive and graded soils." Filters in geotechnical and hydraulic engineering. Balkema, Rotterdam (1993): 357-360.

[14] Wan, Chi Fai, and Robin Fell. "Investigation of rate of erosion of soils in embankment dams." Journal of geotechnical and geoenvironmental engineering 130, no. 4 (2004): 373-380.

[15] Wan, Chi Fai, and Robin Fell. Experimental investigation of internal instability of soils in embankment dams and their foundations. University of New South Wales, School of Civil and Environmental Engineering, 2004.

[16] Li, Maoxin, and R. Jonathan Fannin. "Comparison of two criteria for internal stability of granular soil." Canadian Geotechnical Journal 45, no. 9 (2008): 1303-1309.

[17] Motagh, Mahdi, Thomas R. Walter, Mohammad Ali Sharifi, Eric Fielding, Andreas Schenk, Jan Anderssohn, and Jochen Zschau. "Land subsidence in Iran caused by widespread water reservoir overexploitation." Geophysical Research Letters 35 , no. 16 (2008). 
[18] Ghanbari, A. "Investigation of soil elasticity module in the alluvial soil of south of Tehran.” Journal of Geology Science, 17: 37. (2009).

[19] Mitchell, James Kenneth, and Kenichi Soga. "Fundamentals of soil behavior." (2005).

[20] Ebadati, N. "Environmental Effects of Underground Water Table Reduction in Tehran City (Iran).” Journal of Environmental Monitoring and Protection. No. 6 (2015): 94-102.

[21] Tehran Disaster Mitigation and Management Organization, http://tdmmo.tehran.ir/Default.aspx?tabid=107.

[22] Pirouzi, A., Eslami, A., Kharaghani, S.,and TavousiTafreshi, Sh. "Analytical and experimental study of land subsidence in south western area of Tehran.” Vitae Revista de la Facultad de Quimica Farmaceutica, ISSN 0121-4004 21, no. 1 (2014).: $233-254$.

[23] Ke, L., and Takahashi, A. "Strength reduction of gap-graded cohesionless soil due to internal erosion-unsaturated soils: theory and practice.” University of Kasetsart, Thailand, ISBN: 978-616-7522-77-7. (2011).

[24] Richards, K. S., and Krishna R. Reddy. "Experimental investigation of initiation of backward erosion piping in soils." Géotechnique 62, no. 10 (2012): 933-942.

[25] Nguyen, Hong Hai, Didier Marot, and Fateh Bendahmane. "Erodibility characterisation for suffusion process in cohesive soil by two types of hydraulic loading." La Houille Blanche 6 (2012): 54-60.

[26] Terzariol, R. E., R. J. Rocca, and M. E. Zeballos. "Suffusion in compacted loessial silts. Interaction with granular filters." In Proceedings of the 18th International Conference on Soil Mechanics and Geotechnical Engineering, Paris 2013. 2013.

[27] Wojtasik, Dariusz. "Evaluation of nonwoven geotextile as a filtration layer for internally unstable soils." Annals of Warsaw University of Life Sciences-SGGW. Land Reclamation 40 (2008): 107-114.

[28] Chen, Rong-Her, Chia-Chun Ho, and Wen-Bin Chung. "The filtration mechanism and micro-observation of soil-geotextile systems under cyclic flows." Journal of GeoEngineering 3, no. 3 (2008): 101-112.

[29] Sun, B. C. "Internal Stability of Clayey to Silty Sands (Ph. D. thesis)." University of Michigan, USA (1989).

[30] Shwiyhat, Nathan, and Ming Xiao. "Effect of suffusion on mechanical characteristics of sand." In Scour and Erosion, pp. 378386. ASCE, 2010.

[31] Moffat, Ricardo, and R. Jonathan Fannin. "A hydromechanical relation governing internal stability of cohesionless soil." Canadian Geotechnical Journal 48, no. 3 (2011): 413-424.

[32] Chegenizadeh, Amin, and Hamid Nikraz. "Experimental Approach to Suffusion and Backward Erosion." Electronic Journal of Geotechnical Engineering 18 (2013): 533-542.

[33] Rahimi, H., Davarzani, H., and Abassi, N. "Physical dispersion in non-cohesive soil and its assessment factors." Iranian Journal of Agriculture Sciences. 55(3) (2004): 541-550.

[34] Walker, Strother H., and David B. Duncan. "Estimation of the probability of an event as a function of several independent variables." Biometrika 54, no. 1-2 (1967): 167-179.

[35] Najafi, E. Khaksar, and A. Eslami. "Assessment of the likelihood of suffusion in alluvial soils: case history." Bulletin of Engineering Geology and the Environment 74, no. 2 (2015): 611-620. 